\title{
Optimasi Penyaluran Bahan Bakar Minyak di Wilayah Maluku Indonesia
}

\author{
Rini Dian Sari ${ }^{a, *}$, Farizal $^{b}$, Djoko Sihono Gabriel ${ }^{c}$ \\ a, b, c Teknik, Teknik Industri, Universitas Indonesia, Jalan Salemba Raya 4, DKI Jakarta, Indonesia, 10430. Email: \\ rydisa@gmail.com
}

\section{A B S T R A C T}

Fossil fuel (BBM) is a vital commodity and has a strategic value for people's lives. On the demand side, the need for $B B M$ tends to increase along with the increasing energy demand for people's lives. Therefore, the distribution system for BBM has to be optimized in order to fulfill the people's demand. The aim of this paper is to optimize vehicle route for BBM distribution in Maluku so that it has minimum cost, distance, and time. The optimization method in this paper is Mix Integer Linear Programming (MILP). Decision variables in this paper are chosen from the most significant variables for BBM distribution in Maluku.

Keywords: Fossil Fuel, Distribution, Mix Integer Linear Programming, variables, system

\section{A B S T R A K}

Bahan Bakar Minyak (BBM) merupakan komoditi yang vital dan mempunyai nilai strategis bagi kehidupan masyarakat. Dilihat dari sisi permintaan, kebutuhan akan Bahan Bakar Minyak (BBM) semakin lama cenderung meningkat seiring dengan meningkatnya kebutuhan energi bagi kehidupan masyarakat. Oleh karena itu, sistem distribusi BBM haruslah dioptimalkan agar kebutuhan masyarakat dapat terpenuhi. Tujuan dari paper ini adalah untuk mengoptimalkan rute kendaraan yang ada dalam pengantaran produk serta meminimalkan biaya, waktu dan jarak tempuh di wilayah Maluku. Metode optimisasi yang digunakan adalah Mix Integer Linear Programming (MILP). Variabel-variabel keputusan yang digunakan dalam model MILP ini diambil dari variabel-variabel yang paling banyak mempengaruhi penyalur distribusi BBM di wilayah Maluku.

Kata Kunci: Bahan Bakar, Distribusi, Mix Integrer Linier Programming, Variabel, Sistem Diserahkan: 11-10-2020; Diterima: 26-12-2020; Doi: https://doi.org/10.29303/emj.v3i2.81

\section{Pendahuluan}

Sistem distribusi BBM tidak hanya mencakup distribusi menggunakan angkutan darat, tetapi juga menyangkut angkutan laut. Hal ini dapat dilihat dari gambar persebaran kuota nasional BBM tahun 2018 seperti berikut.

* Corresponding author.

Alamat e-mail: rydisa@gmail.com 


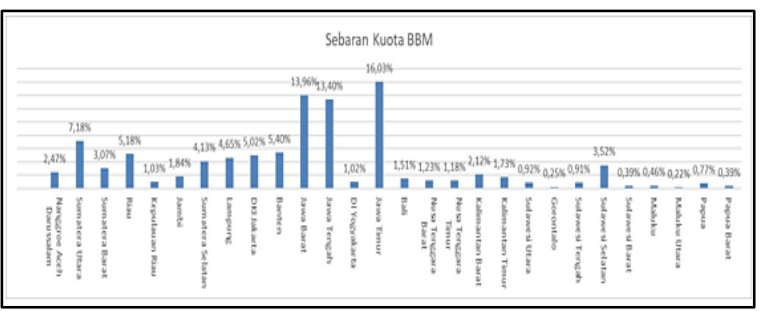

Gambar 1 - Persebaran kuota nasional BBM tahun 2018

(Sumber: BPH Migas)

Pada Gambar 1, terlihat bahwa untuk Indonesia wilayah timur merupakan wilayah pembagian kuota BBM yang masih sedikit dibandingkan dengan Indonesia wilayah barat. Untuk itu diperlukan sistem pendistribusian BBM yang optimal agar tidak terjadi kelangkaan BBM di wilayah tersebut.

Distribusi BBM yang dimaksud dalam artikel ini adalah distribusi BBM ke penyalur Dalam penelitiannya Distribusi ke penyalur ini sudah direview dengan detail oleh Lima et al (2016). Selain itu, Kazemi dan Szmerekovsky (2015) juga memandang masalah ini dengan asumsi transportasi multi-mode.

Berdasarkan hal tersebut di atas, maka studi ini bertujuan untuk melakukan optimalisasi penyaluran BBM di wilayah Maluku dengan mempertimbangkan tingkat persediaan BBM, lama distribusi BBM, volume BBM yang didistribusikan, jumlah dan moda transportasi, Waktu serta jarak antar wilayah penyalur yang berbeda dengan menggunakan Mixed Integer Linear Programming Model.

\section{Metode Penelitian}

Mix Integer Linear Programming (MILP) adalah salah satu metode pemrograman linear bilangan bulat dalam mengalokasikan sumber daya yang terbatas untuk mencapai nilai optimum tertentu.

Penelitian ini mengacu pada spesifikasi model empiris dari Yasaman dan Szmerekovsky (2015) yang melakukan studi di Amerika Serikat dengan melakukan beberapa modifikasi terkait pengukuran variabel Adapun persamaan yang digunakan pada penelitian ini adalah sebagai berikut.

$$
\begin{aligned}
& Z=\sum_{s} P_{s}\left(\sum_{i, j, k}\left(X T_{i, k, s} \times C T_{i, j k}+X R_{i, j, s} \times C R_{i, j k}+X S_{i, j, s,} \times C S_{i, j k}\right)+\sum_{i, j, k}\left(X P_{i, l, k, s} \times C P_{i, j k}\right)\right. \\
& \left.+\sum_{i k}\left(S h P_{i, k} \times X S h_{i, k s}\right)+\sum_{l t r k}\left(E x P_{t r k} \times X E x_{t r k, s}\right)+\sum_{i k}\left(X I_{i, k s} \times I C_{i k}\right)\right)
\end{aligned}
$$

\section{Fungsi tujuan}

Langkah berikutnya adalah membuat model dan menyelesaikan sebuah permasalahan MILP. Masalah yang akan diselesaikan adalah bagaimana menemukan rute distribusi BBM optimal di wilayah Maluku.

Langkah pertama membuat lokasi acak untuk Depot Terminal Transit, Pusat Distribusi (Depot), dan SPBU yaitu dengan mengubah nilai skala dari N, yang membuat ukuran skala volume dan distribusi, dan juga banyaknya titik serta kerapatannya tidak tergantung $\mathrm{N}$.

\section{a. Lokasi}

Untuk nilai $N$ yang diberikan, misal terdapat $f$ Terminal Bahan Bakar Minyak (TBBM), terdapat $s$ SPBU, dan terdapat $w$ sentral distribusi. Maka ada $f N^{2}$ depot terminal transit, $w N^{2}$ sentral distribusi, dan $s N^{2}$ SPBU. Semua lokasi tujuan pada suatu grid dengan beda bilangan bulat antara $l$ dan $N$ pada arah $x$ dan $y$. Agar titik-titik tersebut ada pada lokasi yang berbeda, maka harus memenuhi nilai $f+w+s \leq 1$. Dalam contoh ini, $N=20, f=0.05, w=0.05$, and $s=0.1$.

\section{b. Volume dan pendistribusian}

Ada $P$ produk BBM, dimana $P=3$. Permintaan untuk masing-masing produk $\mathrm{P}$ pada SPBU $s$ adalah $d(s, p)$. Permintaan adalah volume yang dapat dijual dalam jangka waktu tertentu. Salah satu konstrain pada model ini adalah permintaan tepat terpenuhi. Kapasitas konstrain pada TBBM dan sentral distribusi adalah sebagai berikut.

- $\quad$ Volume produk $p$ pada TBBM $f$ lebih kecil dari $p c a p(f, p)$.

- Kapasitas sentral distribusi w adalah wcap $(w)$.

- Jumlah produk $p$ yang bisa di distribusikan dari sentral distribusi ke SPBU dalam waktu tertentu kurang dari $\operatorname{turn}(p) * w c a p(w)$, dimana $\operatorname{turn}(p)$ adalah rata-rata penurunan produk $p$.

Asumsikan masing-masing SPBU menerima asupan hanya dari satu sentral distribusi. Permasalahan dari kasus ini adalah menentukan jalur paling murah dari SPBU ke sentral distribusi. 


\section{c. Biaya}

Biaya pendistribusian produk dari Depot Terminal Transit ke sentral distribusi, dan dari sentral distribusi ke SPBU, tergantung pada jarak antara titik, dan pada jenis produk. Jika $\operatorname{dist}(a, b)$ adalah jarak antara titik $a$ dan $b$, dan biaya shipping satu produk $p$ antara titiktitik adalah jarak waktu biaya transportasi $t \operatorname{cost}(p)$ :

$$
\operatorname{dist}(a, b) * t \operatorname{cost}(p) \text {. }
$$

jarak pada contoh ini jarak antar titik, yaitu $L_{l}$ biaya per liter sebuah produk $p$ adalah $p \operatorname{cost}(f, p)$. Pengolahan data setelah hasil coding dan perhitungan dilakukan dengan menggunakan fitur MILP pada Aplikasi Matlab.

\section{Hasil dan Pembahasan}

Asumsi yang digunakan dalam artikel ini adalah setiap SPBU menerima semua produk dari satu sentral distribusi. Variabel keputusannya adalah sebagai berikut.

$$
\begin{aligned}
x(p, f, w)= & \text { jumlah produk } \mathrm{p} \text { yang di } \\
& \text { distribusikan dari TBBM ke pusat } \\
& \text { distribusi } \\
y(s, w)= & \text { variabel biner yang menunjukkan } \\
& \text { aktif atau tidaknya pustat distribusi. }
\end{aligned}
$$

Sedangkan, fungsi objektifnya adalah sebagai berikut:

$$
\begin{aligned}
& \sum_{f} \sum_{p} \sum_{w} x(p, f, w) \cdot(p \cos t(f, p)+\operatorname{tcost}(p) \cdot \operatorname{dist}(f, w)) \\
& +\sum_{s} \sum_{w} \sum_{p}(d(s, p) \cdot \operatorname{tcost}(p) \cdot \operatorname{dist}(s, w) \cdot y(s, w)) .
\end{aligned}
$$

Adapun konstrainnya adalah sebagai berikut.

- Kapasitas BBM

$$
\sum_{w} x(p, f, w) \leq p c a p(f, p)
$$

- Permintaan

$$
\sum_{f} x(p, f, w)=\sum_{s}(d(s, p) \cdot y(s, w))
$$

- Kapasitas pusat distribusi

$$
\sum_{p} \sum_{s} \frac{d(s, p)}{\operatorname{turn}(p)} \cdot y(s, w) \leq w c a p(w)
$$

- Keterhubungan antar SPBU

$$
\sum_{w} y(s, w)=1
$$

- Ketaknegatifan

$$
x(p, f, w) \geq 0
$$

- $\quad$ Nilai biner

$$
y(s, w) e[0,1]
$$

Variabel $x$ harus bilangan bulat dan variabel $y$ haruslah biner. Oleh karena itu, penyelesaian masalah optimisasinya menggunakan MILP. Berikut diberikan hasil grafik optimasinya.

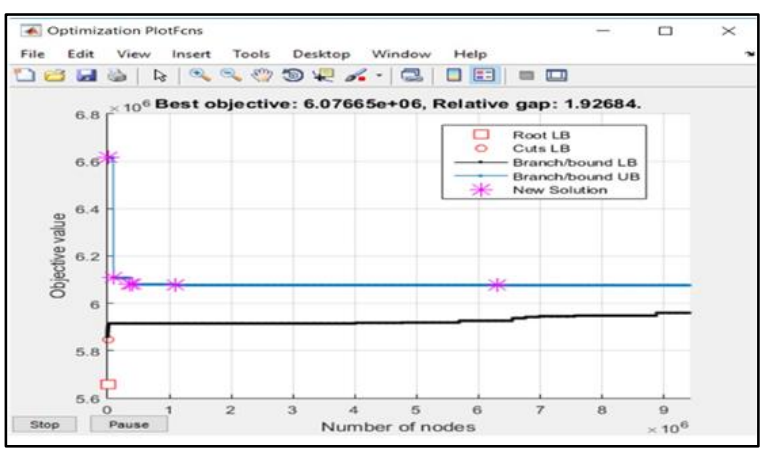

Gambar 2 - Hasil grafik optimasi

Hasil Pengolahan data distribusi BBM dengan Aplikasi Matlab dapat dilihat dalam grafik hasil pemetaan berikut.

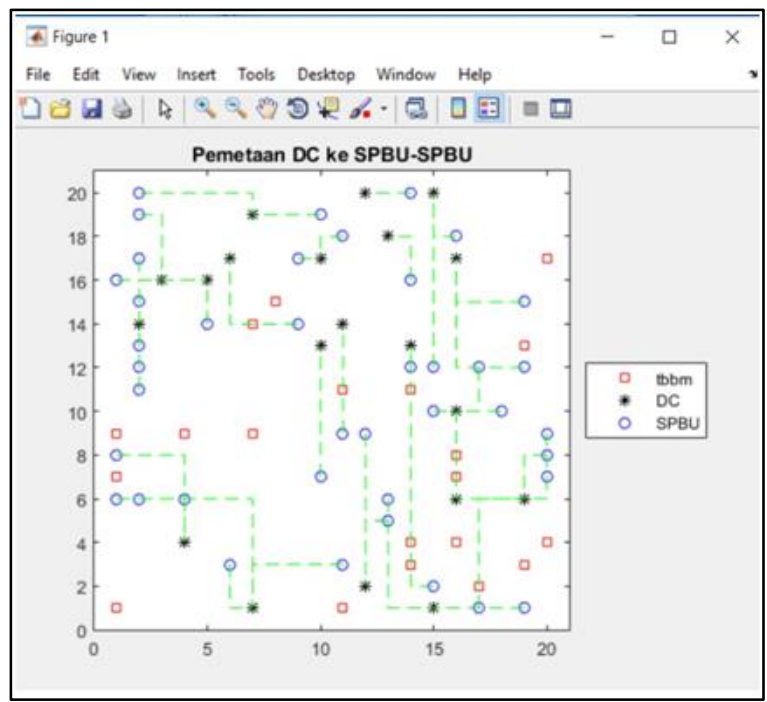

Gambar 3 - Hasil pengolahan data dengan aplikasi Matlab 


\section{Kesimpulan dan Saran}

Dari hasil penelitian pada studi kasus penyaluran Bahan Bakar Minyak di wilayah Maluku, diperoleh beberapa kesimpualan antara lain :

1. Penentuan rute penyaluran Bahan Bakar Minyak dengna menggunakan algoritma dari metode MILP telah berhasil meminimalkan rute dalm pengiriman BBM.

2. Total jarak tempuh dan biaya penyaluran telah turun dari yang sebelumnya, serta telah memaksimalkan rute kendaraan dalam pengiriman.

3. Pemanfaatan dengan menggunakan kendaraan multi produk dalam sekali trip dapat mengefisiensikan biaya pengiriman karena dapat mengurangi jumlah mobil tangki yang beroperasi.

Adapun saran yang diharapkan adalah bahwa kekurangan penelitian ini dapat disempurnakan pada penelitian selanjutnya. Salah satunya dengan mempertimbangkan factor cuaca serta geografis pada suatu wilayah dalam menentukan biaya serta kelancaran suatu pengiriman serta penyaluran BBM kepada penyalur.

\section{DAFTAR PUSTAKA}

Adams, F. G., Griffin, J. M. (1972). An economiclinear programming model of the US petroleum refining industry. J. Am. Stat. Assoc. 67(339), pp. $542-551$.

Adebayo, A. and Dada A. S. (2008). An evaluation ofthe causes of oil pipeline incidents in oil and gas industries in Niger Delta Region of Nigeria. Journal of Engineering and Applied Sciences, 3(3), pp. 279-281.

Akpoghomeh, O.S. and Badejo, D. (2006). Petroleum product scarcity: a review of the supply and distribution of petroleum products in Nigeria. OPEC Review, 30(1), 2740.

Al-Qahtani, K., Elkamel, A. (2008). Multisite facility network integration design and coordination: an application to the refining industry. Comput. Chem. Eng. 32(10), pp. 2189-2202.

An, H., Wilhelm, W.E., and Searcy, S.W. (2011). Biofuel and petroleum-based fuel supply chain research: a literature review. Biomass and Bioenergy, 35(9), pp. 3763-3774.

An, H., Wilhelm, W.E., and Searcy, S.W. (2011). Biofuel and petroleum-based fuel supply chain research: a literature review. Biomass Bioenergy 35(9), pp. 3763-3774.
Anon. (2011). Petroleum liquids pipelines continue to increase transported volumes. Pipeline Gas J. 238(3), pp. 48-51

Aronofsky, J. and Williams, A. (1962). The use of linear programming and mathematical models in under-ground oil production. Manage. Sci., 8(4), pp. 394-407.

Auwal, U. and Mamman J.A. (2012). Thedownstream sector: An assessment of petroleum products supply in Nigeria [online]. $5^{\text {th }}$ Annual NAEE/ IAEE International Conference, Abuja, Nigeria. Available at: http://naee.org.ng/files/Auwal_Mamman\%20Full $\% 20$ Paper\%20NAEE2012\%20( 2).pdf? [Accessed 20 April 2015].

Bravo, J. J. and Vidal, C. J. (2013). Freight transportation function in supply chain optimization models: a critical review of recent trends. Expert Syst. Appl. 40(17), pp. 6742-6757.

Briggs, C.A., Tolliver, D., and Szmerekovsky, J. (2012). Managing and mitigating the upstream petroleum industry supply chain risks: leveraging analytic hierarchy process. Int. J. Bus. Econ. Perspect, 7(1).

Catchpole, A. R. (1962). The application of linearprogramming to integrated supply problems in the oil industry. Operational Research Society, 13(2), pp. 161-169.

Chryssolouris, G., Papakostas, N., and Mourtzis, D., (2005). Refinery short-term scheduling with tank farm, inventory and distillation management: an integrated simulation based approach. Eur. J. Oper. Res., 166(3), pp. 812-827.

Furchtgott-Roth, D. (2013). Pipelines are safest fortransportation of oil and gas [online]. Energyand Environment, Manhattan Institute for Policy Research, 23, pp. 1-10. Available from: http://www.manhattaninstitute.org/pdf/ ib_23.pdf [Accessed 10January 2015].

Kazemi, Y., Szmerekovsky, J. (2015). Transportation Research Part E 83, pp. 111-125. 